IRA-International Journal of Technology \&

Engineering

ISSN 2455-4480; Vol.08, Issue 02 (August 2017)

Pg. no. 28-38

Institute of Research Advances

https://research-advances.org/index.php/IRAJTE

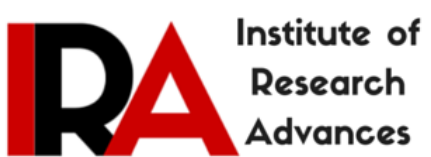

\title{
An Optimization Procedure for Overhead Gantry Crane Exposed to Buckling and Yield Criteria
}

\author{
Ali Ahmid ${ }^{1}$, Van N. Le ${ }^{2}$ and Thien M. Dao ${ }^{3}$ \\ 1,2,3 Department of Mechanical Engineering, École de Technologie Supérieure, 1100, rue Notre- \\ Dame Ouest, Montréal (Québec) H3C 1K3, Canada.
}

Type of Review: Peer Reviewed.

DOI: http://dx.doi.org/10.21013/jte.v8.n2.p3

\section{How to cite this paper:}

Ahmid, A., Le, V., Dao, T. (2017). An Optimization Procedure for Overhead Gantry Crane Exposed to Buckling and Yield Criteria. IRA International Journal of Technology \& Engineering (ISSN 2455-4480), 8(2), 28-38. doi:http://dx.doi.org/10.21013/jte.v8.n2.p3

(C) Institute of Research Advances.

\section{(cc) $\mathrm{BY}-\mathrm{NO}$}

This work is licensed under a Creative Commons Attribution-Non Commercial 4.0 International License subject to proper citation to the publication source of the work.

Disclaimer: The scholarly papers as reviewed and published by the Institute of Research Advances (IRA) are the views and opinions of their respective authors and are not the views or opinions of the IRA. The IRA disclaims of any harm or loss caused due to the published content to any party.

Institute of Research Advances is an institutional publisher member of Publishers Inter Linking Association Inc. (PILA-CrossRef), USA. The institute is an institutional signatory to the Budapest Open Access Initiative, Hungary advocating the open access of scientific and scholarly knowledge. The Institute is a registered content provider under Open Access Initiative Protocol for Metadata Harvesting (OAI-PMH).

The journal is indexed \& included in WorldCat Discovery Service (USA), CrossRef Metadata Search (USA), WorldCat (USA), OCLC (USA), Open J-Gate (India), EZB (Germany) Scilit (Switzerland), Airiti (China), Bielefeld Academic Search Engine (BASE) of Bielefeld University, Germany, PKP Index of Simon Fraser University, Canada. 


\begin{abstract}
The current study presents a general optimization procedure that could be used in designing of various structural applications. To validate the performance of the proposed procedure, a real life application of a custom welded I-Beam gantry crane is selected. The crane is composed of three rectangular plates with the same length and different thicknesses and widths welded together by full penetration welds over the span length to form an I-Beam profile. The thicknesses and widths of plates are to be optimized to have the minimum cross section area while respecting yield, buckling, deflection and fatigue criteria. A mathematical procedure based on Timoshenko beam theory and Crane Manufacturers Association of America (CMAA) in combination with the Genetic Algorithm (GA) is presented, and a Mathcad code is implemented to find the optimal I-Beam cross section dimensions. Nine examples are introduced for 8,12 and $20 \mathrm{~m}$ crane span subjected to 10 , 20 and 40-toncapacities. It is noticed that the optimized I-section configurations always show narrow and thick lower flange, wider and thinner upper flange and tall and very thin web. Theupper flange local buckling and the lateral buckling limits are achieved for all nine cases, $75 \%$ of cases for the web buckling limit, about 33\% of cases for the fatigue and yield limits whereas the maximum deflection constraint is never critical. The obtained results were verified using ANSYS Workbench software with a 3D Solid Finite Element model and shown good agreement, which confirms that the proposed procedure is efficient.
\end{abstract}

Keywords: optimization; I-beam; yield; buckling; design criteria; finite element.

\title{
Introduction
}

The gantry cranes are frequently used for different industrial applications. According to CMAA 74-2010 [1], the cranes in real life engineering are classified into five main classes based on their service capacity: standby, light, moderate, heavy and severe service cranes. The overhead gantry crane type is widely used to serve small or medium duty jobs, like a repair shop, buildings service or in a machine shop. The lightweight crane with high capacity design depicts an essential requirement of the industry. To reach such requirement, a customized I-beam crane is a motivating optimization research. Even though standard I-Beam profiles are available, they are just limited to some standard dimensions, which are usually far from the optimum design. The crane weight, concerning initial standard profiles design, could be reduced up to $10 \%$ using an optimized beam [2].

Several researches have been conducted on optimization of customized and standard crane beams with different profiles. Gasaet al.[3], developed a numerical model of flange local stresses under the wheels acting points to determine the final dimension of the I-beam girder. The numerical example of 12.5 -ton capacity and $25 \mathrm{~m}$ span with three different wheel thicknesses demonstrated. The mathematical and FE analysis results compared to show an acceptable error range of 6 to $15 \%$.Also, they mentioned that the lower flange deflection has a great influence on the final girder dimensions.

Other researchers have worked on optimization of the box profile girders [4, 5 and 6]; they had, in general, the similar procedure of optimization but they used different optimization tools. Their objective was investigating the same concept of weight-strength ratio using theoretical optimization routines backed up by Finite Element (FE) simulation.

Qu et al. [4] proposed a modified Ant Colony Optimization (ACO) algorithm with new local search technique using mutation and applied it to solve nonlinear optimization problems having discrete variables. The developed algorithm of Ant Colony Algorithm with Mutation-based (ACAM) used to determine optimal crane design variables and found to be faster by about $20 \%$ compared to the genetic algorithm (GA) and by $11 \%$ compared to particle swarm algorithm (PSO). Furthermore, it always gives aglobally optimized solution, while the original ACO algorithm may stick at some local solution and fail to go further.

Zuberiet al. [5], examined the effect of rolling load on welded box cross section-crane girderregarding buckling and compression stresses in the flange. The volume of the girder considered as an objective function subjected to the stress and deflection criteria constraints. The built-in MS-Excel nonlinear optimization solver, called Generalized Reduced Gradient (GRG), employed to give preliminary optimized design variables. The obtained values are then 
used as initial inputs to ANSYS code that can handle more accurate stress and deflection calculations for verification purpose and do further optimization if needed.

Kumar et al. [6] conducted research that aims to optimize the weight of Electrical Overhead Travelling (EOT) Crane Bridge girder by adding sufficient stiffeners along the girder plate instead of increasing plate thickness. He used mathematical modeling and Finite Element Analysis to investigate the effect of adding stiffeners and then verify the optimal design experimentally. His work concluded that the plate stability could be increased four times using stiffeners without the need to increase the plate thickness.

Liuet al.[2], carried out a parametric FE study of a doubly trolley box-girder using APDL tool in conjunction with a Matlab code that handles the crane parameters. A three-dimensional girder model subjected to various loading conditions established to predict the limit of load-bearing capacity. Two different optimization algorithms, Arc Length Algorithm (ALA) and Nonlinear Stabilization Algorithm (NLA), used in sequence to overcome the optimization failures. The obtained results of their work shown a significant weight reduction of the girder by $16 \%$ compared to the original design.

Few publications about the customized I-beam crane girder subjected to yield and buckling criteria are reported. Therefore, the current paper extends the similar techniques mentioned above to optimize custom I-Beam crane designs. Three rectangular plates having the same length $(\mathrm{L})$ and different thicknesses and widths welded by continues full penetration welds to form a custom I-Beam crane design, see Fig.3.The live load and the beam span are imposed while each plate thickness and width are considered as design variables that need to be determined to have the minimum weight that respecting the yield, buckling, deflection and fatigue criteria. However, The mathematical calculations based on Cranes Manufacturer Association of America (CMAA) design procedure and the Hybrid Genetic algorithm (GA) are used to find the optimal dimensions of the cross section that satisfy the design constraints. A Mathcad platform is written to handle these calculations. Also, a 3D-solid FE model created; stress analyzed and optimized using ANSYS Workbench software.

\section{Design optimization procedure}

Highly sophisticated optimization techniquesare needed to achieve an optimal crane design that considers yield, buckling, deflection and fatigue criteria. Such techniques must deal with iterative schemes that require a programming language or a mathematical application such as Mathcad. The general trends of solving such problems in the recent years were emphasizing on carrying out a mathematical solution, an FE solution or a math-FE combined solution. The combined solution conducted in two different ways [5]; the first way is carrying out both types of analysis techniques with the same initial values and takes the most optimal results between them. The second one uses the output results of the mathematical solution as input values of an FE solution. The present study follows the second method. The flowchart Fig.1 illustrates the proposed procedure. It starts with problem formulation, i.e., defines design variables, objective function, etc. Follows that entering the data of crane, which are in our case the span length, the rated load, and the material; then performing the optimization Hybrid Genetic Algorithm (GA) code,the details of which are shown in Fig.2, to give the so called Math-Optimal design variables.The Math-optimal design variables are input as initial variables to the FE Optimization phase using ANSYS Workbench 15 software in which the Response Surface Optimization method is used $[7,8]$. 

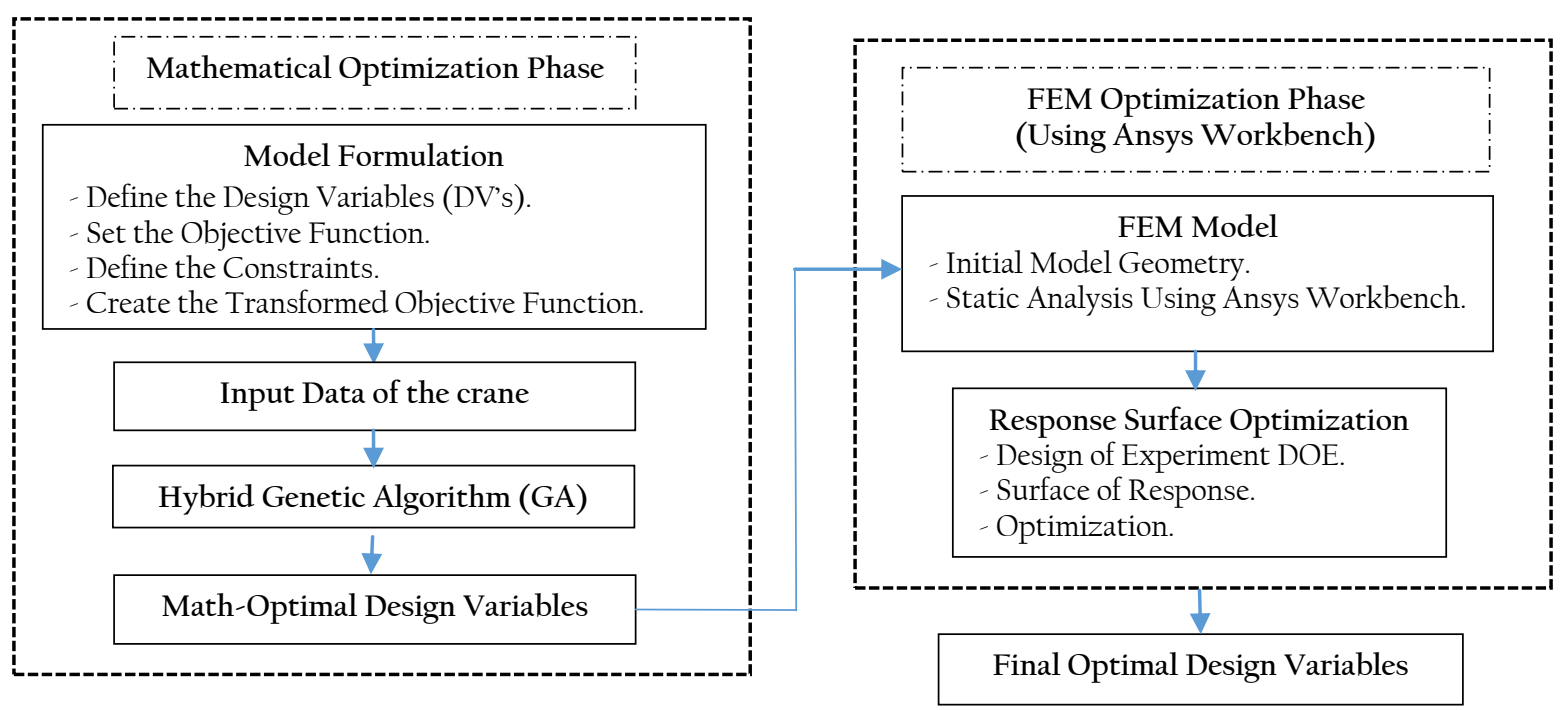

Fig. 1: Proposed design optimization procedure [9]

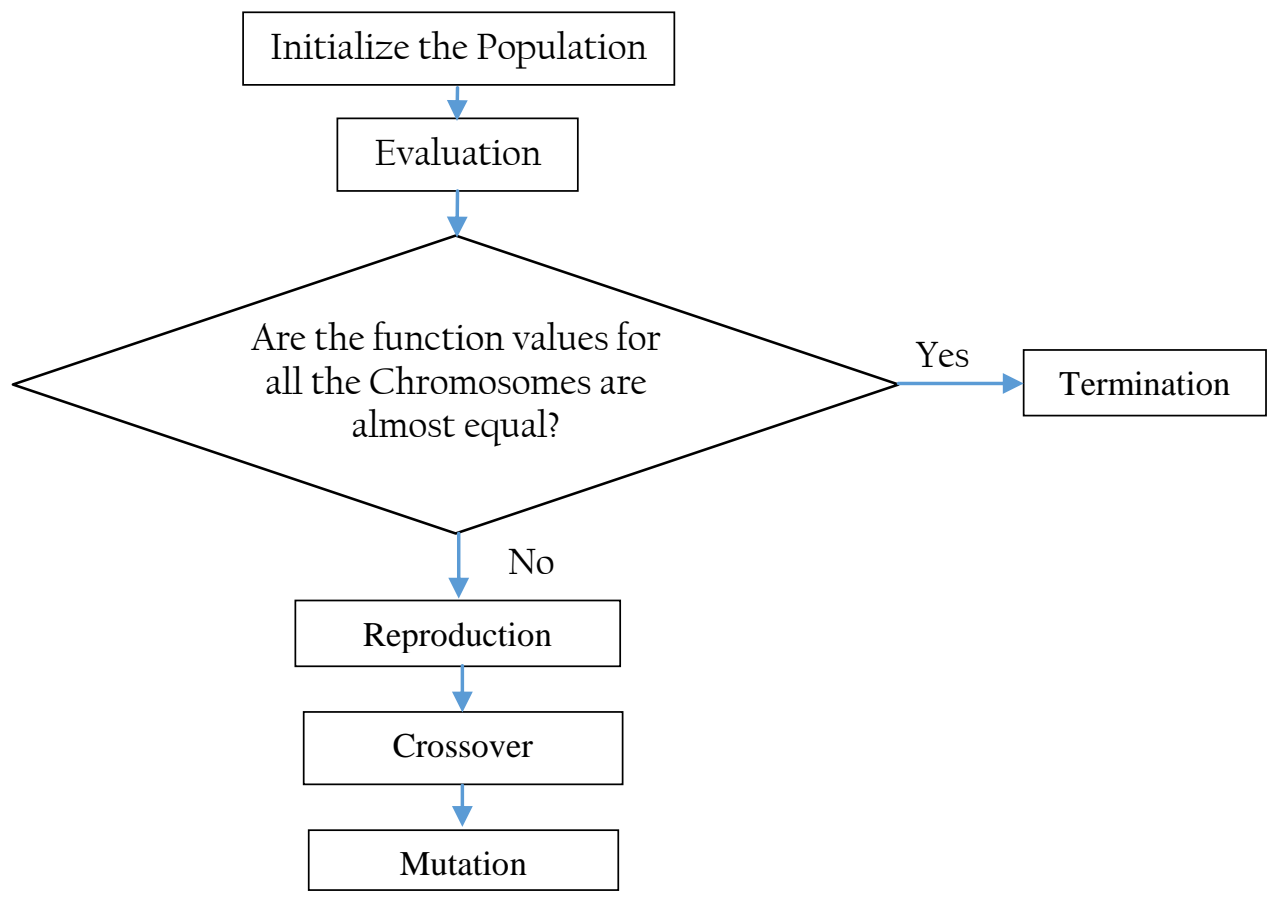

Fig. 2: Hybrid Genetic Algorithm [10] 


\section{Problem description}

The welded I-Beam crane and the loading conditions are shown in Fig. 3. The beam formed by three plates joined by continuous welds over the beam length. They have the same length but different thicknesses and widths; the dimensions and loading conditions defined as follow:
$\mathrm{b}_{1}$ : lower flange width,
$\mathrm{t}_{1}:$ lower flange thickness,
$\mathrm{b}_{2}$ : upper flangewidth,
$\mathrm{t}_{2}:$ upper flangethickness,
$\mathrm{h}:$ web height,
$\mathrm{L}$ : beam span,
$\mathrm{W}_{1}$ : crane weight,
$\mathrm{t}_{3}:$ web thickness,
$\mathrm{W}_{2}$ : live load (Lifting load),

$\mathrm{x}$ : distance of live load from the left end
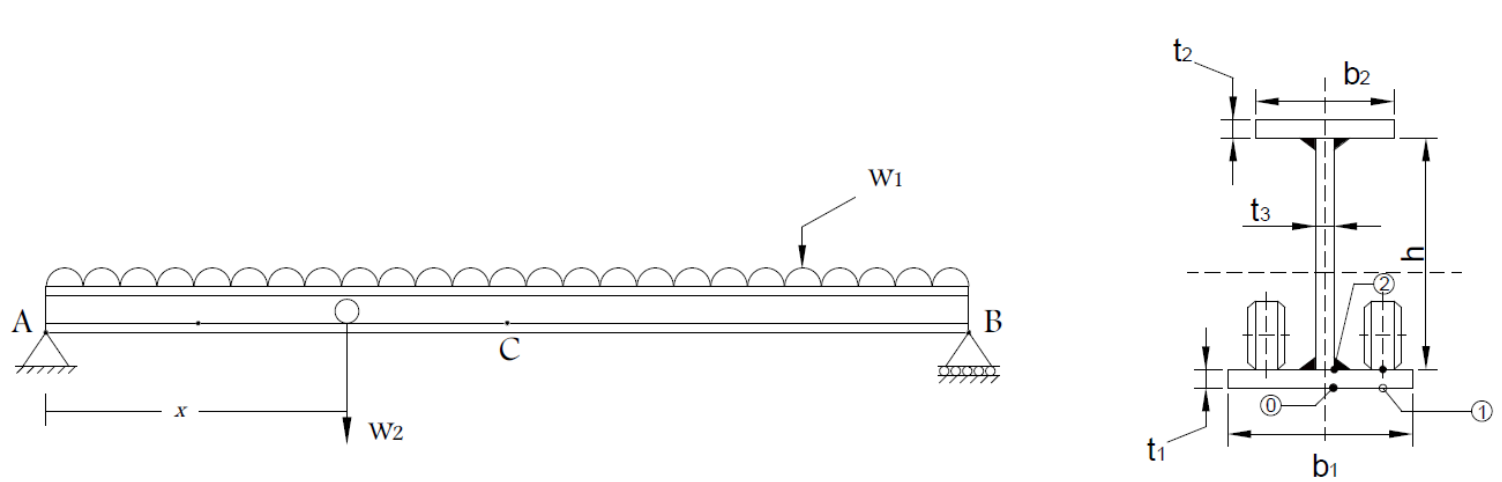

Fig.3: The crane beam dimensions and loading conditions

\section{Objective function}

Where the span length is fixed with a constant cross section area of the crane beam, the weight is just proportional to the cross-section area so that the objective function is defined by the cross-section area, as follows.

$$
f=b_{1} \cdot t_{1}+b_{2} \cdot t_{2}+h \cdot t_{3}
$$

where the parameters b1, t1 ...etc. are shown in Fig. 3.

\section{Design constraints}

The most important criteria of the Crane Manufacturers Association of America specification, known as CMAA742010, are considered and summarized as follows

- Tension stress Constraints (due to gravity and live load) :

$$
\sigma_{\text {comb_max }}-\sigma_{\text {Tallowed }} \leq 0 \quad \text { (CMAA 74-3.4.4.1, [1][2]) }
$$

- Lateral Buckling Constraint:

$$
1.9-\mathrm{f}_{\text {Buckling }} \leq 0 \quad \text { (Timoshenko Beam Theory, [11][16]) }
$$

- Local Buckling Constraints:

$$
\begin{array}{cr}
\mathrm{h} / \mathrm{t}_{3}-260 \leq 0 & \text { (AISC } 2016 \text { sec. F13, [12][7]) } \\
\mathrm{b}_{2} / 2 \mathrm{t}_{2}-260 / \sqrt{\sigma_{\mathrm{y}}} \leq 0 & \text { (CISC handbook p.p5-11, [13][18]) }
\end{array}
$$


- Deflection Constraint :

$$
\delta_{\mathrm{v}}-\mathrm{L} / 600 \leq 0 \quad \text { (CMAA 74-3.5.5, [1][2]) }
$$

- Fatigue Constraint (due to repeated load fluctuation $\Delta \mathrm{W} 2$ only) :

$$
(\Delta \sigma)_{\text {comb }_{\max }}-\Delta \sigma_{\text {allowed }} \leq 0 \quad \text { (AISC } 2016 \text { sec. F13, [12][7]) }
$$

where $\sigma_{\mathrm{comb}}=\sqrt{\sigma_{\mathrm{x}}{ }^{2}+\sigma_{\mathrm{y}}{ }^{2}-\sigma_{\mathrm{x}} \sigma_{\mathrm{y}}+3 \tau_{\mathrm{xy}}{ }^{2}}$ is the Von-Mises equivalent stress;

$\sigma_{\text {Tallowed }}=$ Allowable tension stress, according to CMAA 74;

$\delta_{\mathrm{v}}=$ Maximum vertical deflection

$\Delta \sigma=$ stands for stress range

$\sigma_{\mathrm{Y}}=$ Yield strength

$\mathrm{f}_{\text {Buckling }}=$ Buckling load factor, which means a factor to be multiplied to all applied loads to produce linear buckling of the structure. This factor is given initially by the linear buckling theory, e.g., Timoshenko formulas or by an FE model. It is valid only if the linear buckling stress, which is $\sigma_{\mathrm{Cr} 0}=\left.\mathrm{f}_{\text {Buckling }} *\right|_{\text {oupper flangel }}$, is less than $1 / 2 * \sigma_{\mathrm{Y}}$; otherwise, it must be modified to take into account the plastic deformation during buckling. The corrected critical stress calculated using Johnson's empirical formula, $\sigma_{c r}=\sigma_{Y} \cdot\left[1-\frac{\sigma_{Y}}{4 . \sigma_{c r 0}}\right]$, [14] and the corrected buckling load factor is given by $\frac{\sigma_{c r}}{\left|\sigma_{\text {upperflang }}\right|}$

\section{Objective function transformation}

The exterior point penalty function is used to transform the constrained optimization problem into an unconstrained problem. The general form of the transformed objective function is:

$$
F\left(X, r_{h}, r_{g}\right)=f(X)+r_{h}\left[\sum_{k=1}^{i} h_{k}(X)^{2}\right]+r_{g}\left[\sum_{j=1}^{m}\left(\max \left\{0, g_{j}(X)\right\}\right)^{2}\right]
$$

where $X$ is the vector representing the design variables, $h_{k}$ is the kth equality constraint if any, $g_{j}$ is the $j^{\text {th }}$ inequality constraint, $r_{h}$ and $r_{g}$ are two additional variables called penalty multipliers[15].

\section{Numerical examples}

Nine cases defined by three span lengths $(8,12$ and $20 \mathrm{~m})$ and three rated loads $(10,20$ and 40 tons) are selected as numerical examples. The crane specifications are listed in Table 1 . The material used for the crane is $350 \mathrm{~W}$ structure steel with yielding strengthS $\mathrm{S}_{\mathrm{y}}=350 \mathrm{MPa}$, density $=7850 \mathrm{~kg} / \mathrm{m}^{3}$, Young's modulus $\mathrm{E}=200 \mathrm{GPa}$, shear modulus $\mathrm{G}=77 \mathrm{GPa}$ and Poisson's ratio $v=0.3$.

Table 1 Crane Specifications according to CMAA 74-2010

\begin{aligned} & \hline Variable \multicolumn{1}{c}{ Value/Units } \\ & \hline Rated Capacity: 10,20 or 40 tons \\ & Service Class D: Heavy Service \\ & Load Class L3: Normalload $=2 / 3$ of rated load \\ & Cycles Class N2: Up to 500000 cycles \\ & Span: 8,12 or $20 \mathrm{~m} \\ &$ Trolley Weight: 1 tons \\ & Other equipment Load: 1 tons \\ & Bridge Wheel per rail: One on each side \\ & \hline\end{aligned}


The mathematical optimization procedure, described in section 2, programmed using Mathcad Code[16]. Table 2 summarizes the values of GA parameters.

Table 2 Genetic Algorithm Parameters

\begin{aligned} & \hline Parameter Used Value \\ & \hline Number of Variables: $\mathrm{NV}=6 \\ &$ Population size: $\mathrm{NP}=120 \\ &$ Probability of crossover: $\mathrm{PC}=0.85 \\ &$ Probability of mutation: $\mathrm{PM}=0.05 \\ &$ Mutation Parameter: $\mathrm{BM}=5 \\ &$ Maximum generation number: $\mathrm{GMAX}=300 \\ &$\hline\end{aligned}

\section{Finite element model}

The Fig. 4 shows a 3D drawing of an I-Beam crane, the Fig. 5 (a) shows the overall view of a 3D-solid FE model of the crane created in ANSYS Workbench $\odot$ 15, and the Fig. 5 (b) shows a local zoom around the contact region between the lower flange and the wheels. The lower edges at ends are vertically supported, and the loads to be considered are composed of the distributed gravity load W1 (weight of the beam), and the concentrated load W2 applied on the wheels, W2 being the combination of the lifted load, the weights of trolley and hoist.

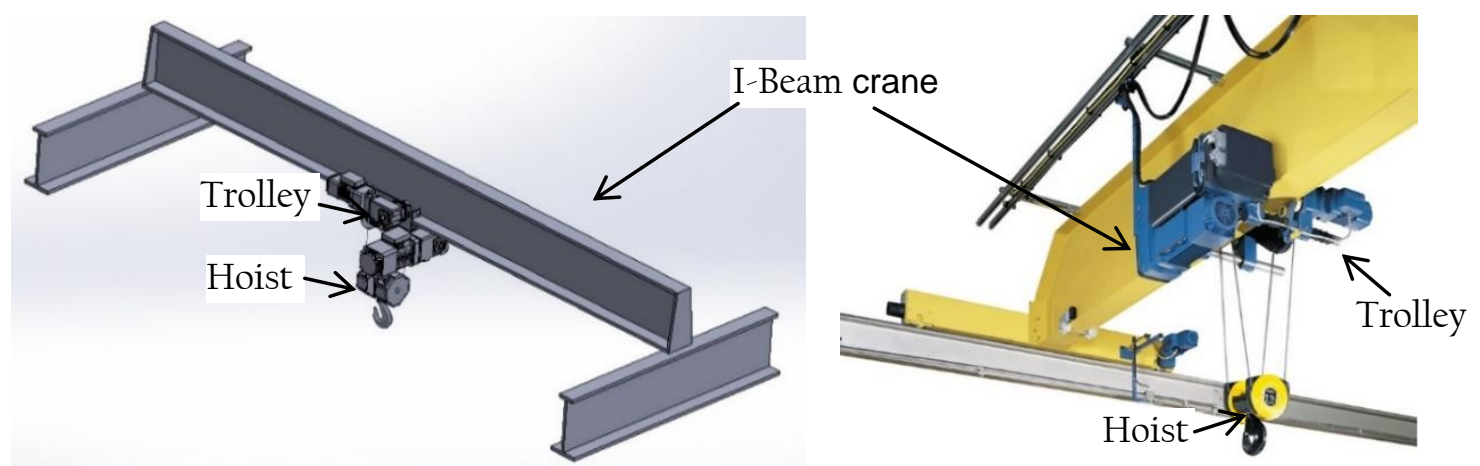

Fig. 4. Three-dimensional images of the crane

All loads are adjusted by factors according to CMAA 74 Specifications. The rated load plus gravity are applied when considering the yield and buckling constraints, inequalities (2) to (5), while the normalload fluctuation, which is just $2 / 3$ of rated load without gravity, is applied when considering the deflection and fatigue constraints, (6) and (7). For the FE model, the Surface Response Optimization method [7, 8], already integrated into ANSYS Workbench, is used. This model contains about 28300 nodes

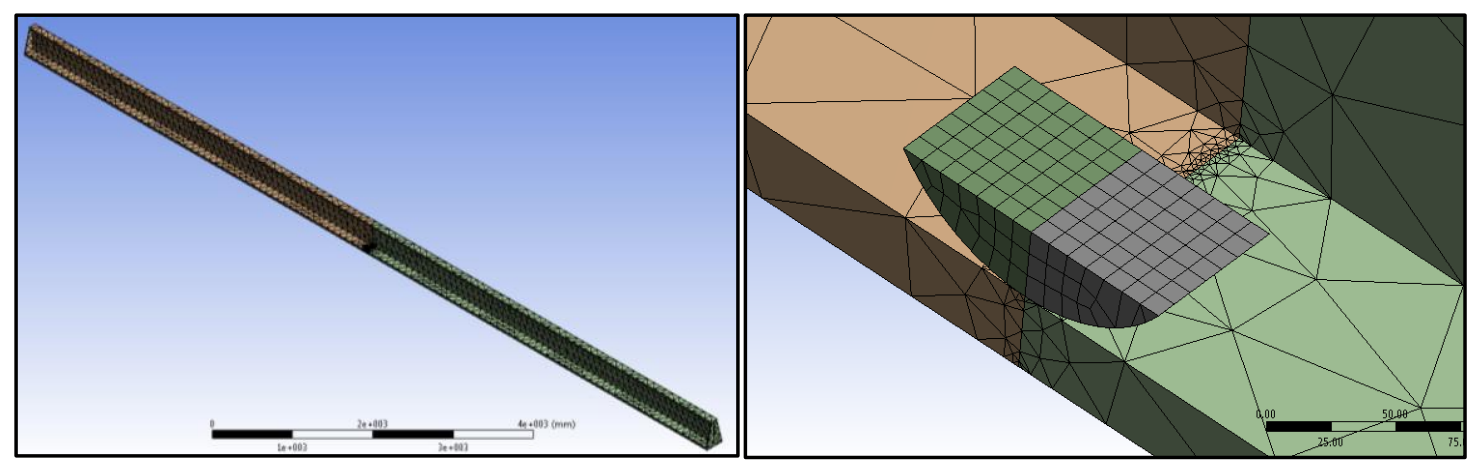

Fig. 5. Finite Element Model of the crane 


\section{Numerical results}

For reducing calculation time, it needs to input the reasonable lower and upper bound values of each design variable. The bounds used in all 9 cases are shown in Table 3.

Table 3. Lower bound and upper bound of design variables in $\mathrm{mm}$

\begin{tabular}{rcccccc}
\hline Variables & $\mathbf{t}_{\mathbf{1}}$ & $\mathbf{b}_{\mathbf{1}}$ & $\mathbf{t}_{\mathbf{2}}$ & $\mathbf{b}_{\mathbf{2}}$ & $\mathbf{t}_{\mathbf{3}}$ & $\mathbf{h}$ \\
\hline Lower bound & 2 & 150 & 2 & 150 & 3 & 250 \\
Upper bound & 100 & 600 & 100 & 600 & 100 & 1675 \\
\hline
\end{tabular}

The optimized design variables for nine cases are presented in the Tables 4.1, 4.2 and 4.3. The Table 4.1 results are for short span cranes with three different rated loads, the Table 4.2's are for intermediate span cranes, and the Table 4.3's are for long span cranes.

Table 4.1 Optimal Design variables and constraint parameters for $8 \mathrm{~m}$ cranes

\begin{tabular}{rccccc}
\hline \multirow{2}{*}{$\mathbf{L}=\mathbf{8} \mathbf{~ m}$} & \multicolumn{2}{c}{$\mathbf{1 0}$ tons } & \multirow{2}{*}{$\mathbf{2 0}$ tons } & \multirow{2}{*}{$\mathbf{4 0}$ tons } & \multirow{2}{*}{ Bounds } \\
\cline { 2 - 4 } & MATH & $\mathbf{F E M}$ & & & \\
\hline $\mathrm{t}_{1}(\mathrm{~mm})$ & 27.82 & 27.98 & 37.88 & 52.62 & {$[2,100]$} \\
$\mathrm{b}_{1}(\mathrm{~mm})$ & 150.01 & 150.0 & 150.16 & 150.04 & {$[150,600]$} \\
$\mathrm{t}_{2}(\mathrm{~mm})$ & 6.99 & 7.43 & 8.38 & 9.08 & {$[2,100]$} \\
$\mathrm{b}_{2}(\mathrm{~mm})$ & 194.20 & 186.1 & 220.18 & 252.14 & {$[150,600]$} \\
$\mathrm{t}_{3}(\mathrm{~mm})$ & 3.00 & 3.00 & 3.19 & 4.38 & {$[3,100]$} \\
$\mathrm{h}(\mathrm{mm})$ & 608.64 & 650.88 & 826.46 & 1137.03 & {$[250,1675]$} \\
Area $(\mathrm{m} 2)$ & 0.00736 & 0.00753 & 0.0102 & 0.0152 & \\
$\sigma_{\text {com_max }}(\mathrm{MPa})$ & 221.9 & 201.9 & 224.9 & 225 & $<=225 \mathrm{MPa}$ \\
$\mathrm{F}_{\text {Buckling }}$ & 1.9 & 1.96 & 1.9 & 1.91 & $>=1.9$ \\
$\mathrm{~h} / \mathrm{t}_{3}$ & 202.876 & 216.96 & 259.37 & 259.88 & $<=260$ \\
$\mathrm{~b}_{2} / 2 \mathrm{t}_{2}$ & 13.895 & 12.524 & 13.14 & 13.887 & $<=13.898$ \\
$\delta_{\mathrm{v}}(\mathrm{m})$ & 0.0074 & 0.0063 & 0.0057 & 0.0043 & $<=0.013 \mathrm{~m}$ \\
$(\Delta \sigma)_{\text {com_max }}(\mathrm{MPa})$ & 166 & 160.1 & 165.9 & 165.2 & $<=166 \mathrm{MPa}$ \\
\hline & & & & & \\
\hline
\end{tabular}

Table 4.2 Optimal Design variables and constraint parameters for $12 \mathrm{~m}$ cranes

\begin{tabular}{rcccc}
\hline $\mathbf{L}=\mathbf{1 2} \mathbf{~ m}$ & $\mathbf{1 0}$ tons & 20 tons & 40 tons & Bounds \\
\hline $\mathrm{t}_{1}(\mathrm{~mm})$ & 27.88 & 53.52 & 54.61 & {$[2,100]$} \\
$\mathrm{b}_{1}(\mathrm{~mm})$ & 179.54 & 150.01 & 206.13 & {$[150,600]$} \\
$\mathrm{t}_{2}(\mathrm{~mm})$ & 10.34 & 12.04 & 13.41 & {$[2,100]$} \\
$\mathrm{b}_{2}(\mathrm{~mm})$ & 287.15 & 334.55 & 372.14 & {$[150,600]$} \\
$\mathrm{t}_{3}(\mathrm{~mm})$ & 3.02 & 3.12 & 4.21 & {$[3,100]$} \\
$\mathrm{h}(\mathrm{mm})$ & 785.98 & 811.78 & 1094.81 & {$[250,1675]$} \\
Area $(\mathrm{m} 2)$ & 0.0104 & 0.0146 & 0.0209 & \\
$\sigma_{\text {com_max }}(\mathrm{MPa})$ & 203.9 & 188.9 & 225 & $<=225 \mathrm{MPa}$ \\
$\mathrm{F}_{\mathrm{Buckling}}$ & 1.9 & 1.9 & 1.9 & $>=1.9$ \\
$\mathrm{~h} / \mathrm{t}_{3}$ & 259.93 & 259.98 & 259.98 & $<=260$ \\
$\mathrm{~b}_{2} / 2 \mathrm{t}_{2}$ & 13.884 & 13.896 & 13.877 & $<=13.898$ \\
$\delta_{\mathrm{v}}(\mathrm{m})$ & 0.0095 & 0.012 & 0.0097 & $<=0.02 \mathrm{~m}$ \\
$(\mathrm{MPa})$ & 163 & 121.3 & 164.1 & $<=166 \mathrm{MPa}$ \\
\hline
\end{tabular}


Table 4.3 Optimal Design variables and constraint parameters for $20 \mathrm{~m}$ cranes

\begin{tabular}{rcccc}
\hline $\mathbf{L}=\mathbf{2 0} \mathbf{~ m}$ & $\mathbf{1 0}$ tons & $\mathbf{2 0}$ tons & 40 tons & Limits \\
\hline $\mathrm{t}_{1}(\mathrm{~mm})$ & 30.14 & 92.15 & 54.41 & {$[2,100]$} \\
$\mathrm{b}_{1}(\mathrm{~mm})$ & 275.88 & 150.29 & 347.13 & {$[150,600]$} \\
$\mathrm{t}_{2}(\mathrm{~mm})$ & 15.06 & 14.98 & 18.1 & {$[2,100]$} \\
$\mathrm{b}_{2}(\mathrm{~mm})$ & 418.41 & 416.3 & 501.7 & {$[150,600]$} \\
$\mathrm{t}_{3}(\mathrm{~mm})$ & 3.29 & 3.36 & 4.72 & {$[3,100]$} \\
$\mathrm{h}(\mathrm{mm})$ & 821.75 & 872.94 & 1226.51 & {$[250,1675]$} \\
Area $(\mathrm{m} 2)$ & 0.0173 & .0230 & 0.034 & \\
$\sigma_{\text {com_max }}(\mathrm{MPa})$ & 202.5 & 199.5 & 218.2 & $<=225 \mathrm{MPa}$ \\
$\mathrm{F}_{\text {Buckling }}$ & 1.9 & 1.9 & 1.9 & $>=1.9$ \\
$\mathrm{~h} / \mathrm{t}_{3}$ & 249.96 & 259.47 & 259.95 & $<=260$ \\
$\mathrm{~b}_{2} / 2 \mathrm{t}_{2}$ & 13.89 & 13.891 & 13.896 & $<=13.898$ \\
$\delta_{\mathrm{v}}(\mathrm{m})$ & 0.025 & 0.032 & 0.023 & $<=0.033 \mathrm{~m}$ \\
$(\Delta \sigma)_{\text {com_max }}(\mathrm{MPa})$ & 157.7 & 94.61 & 166 & $<=166 \mathrm{MPa}$ \\
\hline
\end{tabular}

It is noticed that the lateral buckling and the upper flange local buckling limits are reached for nine over 9 cases, the web buckling limit for 6/9 cases, the yield and fatigue limits for 3/9 cases and the deflection constraint is never critical. In addition, the optimized I-section configurations always show narrow and thick lower flange, wider and thinner upper flange and tall and very thin web. The Fig. 6 approximately illustrates the optimum I-Beam cross sectional configuration for a $20 \mathrm{~m}$ crane subjected to 20 tons lifted load. The comparison between the custom I-beam configuration as shown in Fig. 6 , which has $\mathrm{A}=0.023 \mathrm{~m}^{2}$, and a doubly symmetrical I-beam $(\mathrm{t} 1=\mathrm{t} 2=39.53 \mathrm{~mm}$, $\mathrm{b} 1=\mathrm{b} 2=307 \mathrm{~mm}, \mathrm{t} 3=3.85 \mathrm{~mm}, \mathrm{~h}=996 \mathrm{~mm}$ and $\mathrm{A}=0.028 \mathrm{~m} 2$ ) shows that the customized I-beam could save almost $18 \%$ of the weight. The design parameters given by the Math optimization are then inputted to an FE procedure using ANSYS Workbench 15 with a 3D nonlinearsolid model due to the contact between the wheels and the lower flange. The Surface Response Optimization method in ANSYS Workbench used with considering the same constraints, except the linear buckling constraint, because linear buckling does not work with nonlinear contact models. However, the buckling constraint $\left(f_{\text {Buckling }} \geq 1.9\right.$ ) replaced by an approximate constraint on the slenderness ratio against lateral buckling to give a comparable buckling load factor. This slenderness ratio is given by $\lambda=L / r_{c y}$ where $r_{\mathrm{cy}}$ is the lateral radius of gyration of the effective compression area which is empirically the $2 / 3$ outermost of the compression side of the cross section (see Fig. 6). FE stress calculation with nonlinear contact and optimization procedure is very time consuming;so only one case selected to show FE results, which is the $8 \mathrm{~m}$ and 10-ton case. The slenderness ratio constraint for this case is $\lambda \leq 190$. 


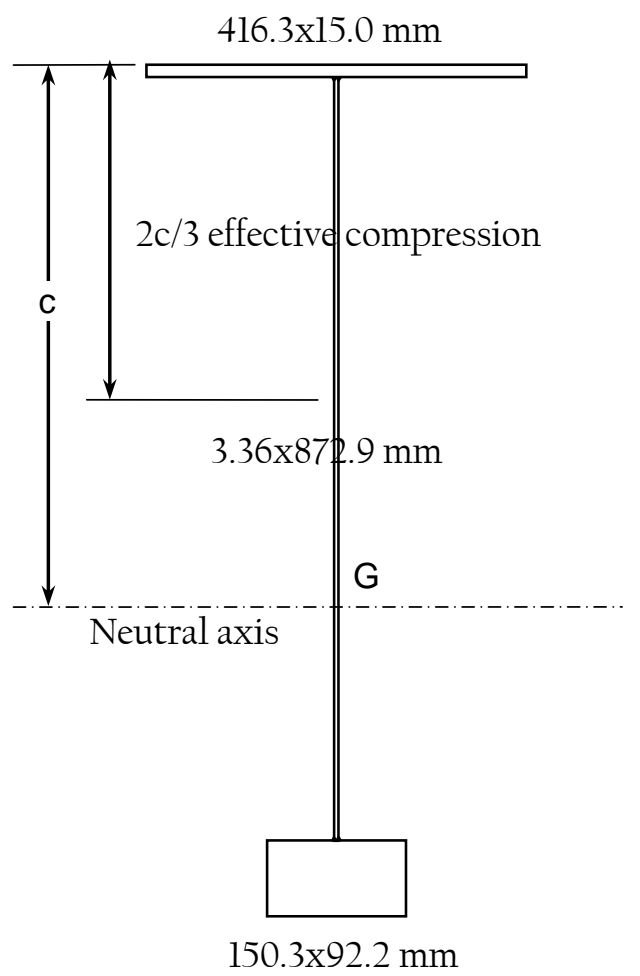

Fig. 6. Optimum configuration of an I-section

The new optimized design parameters given by FE procedure are shown in the FEM column of Table 4.1; theyare slightly different but quite close to the Math results. The Fig. 7 reveals that the maximum Von-Mises stress is in the lower flange right under the wheels.

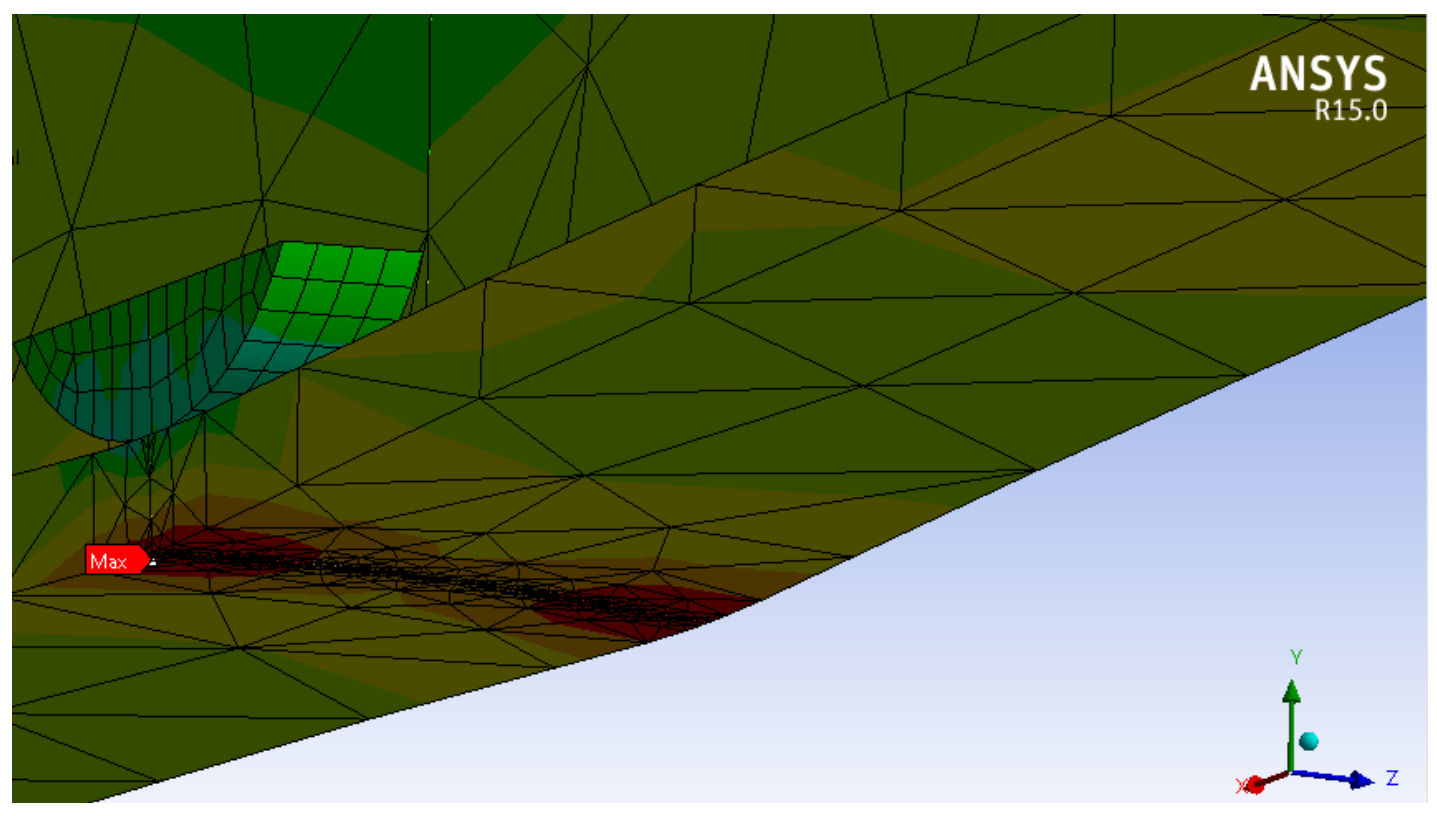

Fig. 7. Location of maximum Von-Mises stress 


\section{Conclusion}

A Hybrid Genetic Optimization Algorithm (GA) and a Mathematical optimization procedure are programmed in Mathcad and successfully applied to custom welded I-Beam cranes with different spans and rated loads subjected to yield, buckling, deflection and fatigue criteria. It is found that the constraints of general lateral buckling and local buckling of the upper flange are always reached for all cases. The web local buckling constraint is critical for about $66 \%$ of cases, the yield and fatigue constraints found critical for $33 \%$ of cases and the deflection constraint is not a problem at all. The optimized custom I-section has a configuration of narrow and thick lower flange, thinner and wider upper flange and the web is talland verythin, which could save about $18 \%$ of weight compared to commercial standard I-Beam. FEM optimization using Surface Response method gives comparable results and confirms that the proposed procedure is efficient.

For future works, the FE optimization taking into account nonlinear buckling due to contact or plasticity constitutes a significant challenge. Furthermore, the optimization procedure with multi objective functions such as weight and cost will also be an interesting future work.

\section{References}

[1] CMAA Specification 74, Specifications for Top Running and Under Running Single Girder Electric Overhead Traveling Cranes Utilizing Under Running Trolley Hoist. (2010). Charlotte, NC: CMAA.

[2] Liu, P. F., Xing, L. J., Liu, Y. L., \& Zheng, J. Y. (2014). Strength Analysis and Optimal Design for Main Girder of DoubleTrolley Overhead Traveling Crane Using Finite Element Method. Journal of Failure Analysis and Prevention, 14(1), 76-86.

[3] Gąska, D., Haniszewski, T., \& Margielewicz, J. (2017). I-beam girders dimensioning with numerical modeling of local stresses in wheel-supporting flanges. Mechanics, 23(3), 347-352.

[4] Qu, X., Xu, G., Fan, X., \& Bi, X. (2015). Intelligent optimization methods for the design of an overhead traveling crane. Chinese Journal of Mechanical Engineering, 28(1), 187-196.

[5] Zuberi, R. H., Kai, L., \& Zhengxing, Z. (2008). Design optimization of EOT Crane Bridge. Eng Opt, 192-201.

[6] Kumar, A., (2016). NUMERICAL AND EXPERIMENTAL BUCKLING ANALYSIS OF CRANE GIRDER. International Journal of Research in Engineering and Technology, 05(06), 192-197. doi:10.15623/ijret.2016.0506037

[7] ANSYS Inc, (November 2011). Workbench Users Guide, Release 15.0 Canonsburg PA, USA.

[8] Lee, H. (2014). Finite element simulations with ANSYS Workbench 15: Mission, KS: Schroff Development Corporation.

[9] Ahmid, A., Le, N., Dao, T. (2017). Optimization procedure for an I-beam crane subjected to yield and buckling criteria. The 2017 International Conference on Innovative Structural Engineering and Mechanics,ASEM17, Seoul, Korea.

[10] Yang, W. Y., Cao, W., \& Chung, T. (2005). Applied numerical methods using MATLAB. Hoboken, NJ: J. Wiley.

[11] Timoshenko, S. P., Gere, J. M., \& Prager, W. (1962). Theory of Elastic Stability, Second Edition. Journal of Applied Mechanics,29(1), 220. doi:10.1115/1.3636481.

[12] AISC. (2016). Specification for Structural Steel Buildings: Design of members for flexure Chicago, IL: American Institute of Steel Construction

[13] CISC (1980). Handbook of steel construction, Third Edition. Markham, ON, Canada.

[14] Popov, E. P. (1976). Mechanics of materials: solutions for problems. Englewood Cliffs, NJ: Prentice-Hall.

[15] Ragsdell, K. M., \& Phillips, D. T. (1976). Optimal Design of a Class of Welded Structures Using Geometric Programming. Journal of Engineering for Industry,98(3), 1021. doi:10.1115/1.3438995

[16] PTC (2011). PTC Mathcad 15 M010 User's Manual. Retrieved August 12, 2016. 